\title{
DEFICIÊNCIA HÍDRICA, TROCAS GASOSAS E CRESCIMENTO DE RAÍZES EM LARANJEIRA ‘VALÊNCIA’ SOBRE DOIS TIPOS DE PORTA-ENXERTO ${ }^{(1)}$
}

\author{
JOSÉ RODRIGUES MAGALHÃES FILHO $\left({ }^{2}\right)$; LUCAS RIOS DO AMARAL $\left({ }^{3}\right)$; \\ DANIELA FÁVERO SÃO PEDRO MACHADO $\left({ }^{2}\right)$; CAMILO LÁZARO MEDINA $\left({ }^{4}\right)$; \\ EDUARDO CARUSO MACHADO $\left(5^{*}\right)$
}

\begin{abstract}
RESUMO
O crescimento e a distribuição do sistema radicular afetam as respostas das plantas à ocorrência de deficiência hídrica. Este trabalho teve como objetivo avaliar em mudas de laranjeira 'Valência' enxertada sobre limoeiro 'Cravo' ou Poncirus trifoliata ('Trifoliata') o crescimento de raízes, as trocas gasosas $\left(\mathrm{CO}_{2}\right.$ e $\left.\mathrm{H}_{2} \mathrm{O}\right)$, o potencial da água na folha e a distribuição de carboidratos nos diversos órgãos, em plantas submetidas à deficiência hídrica. As mudas foram transplantadas para 32 rizotrons, que permitiam a visualização das raízes, sendo 16 para cada porta-enxerto e submetidas ou não à irrigação. A deficiência hídrica às plantas foi aplicada pela interrupção do fornecimento de água às plantas. A condutância estomática decaiu após o quarto dia sem irrigação, causando redução da fotossíntese, da transpiração e da eficiência de carboxilação. O teor de carboidrato total (sacarose + açúcares redutores + amido) em plantas sem estresse foi maior em 'Trifoliata', e entre os tratamentos com deficiência hídrica foi sempre inferior. As massas secas das plantas sem deficiência hídrica foram maiores, em ambos os porta-enxertos. Entre os tratamentos irrigados e não irrigados, o comprimento das raízes dentro de um mesmo tipo de porta-enxerto foram semelhantes. Porém, o comprimento das raízes de laranjeira 'Valência' sobre 'Cravo' foi significativamente maior. Mesmo sob deficiência hídrica e grande queda da produção fotossintética, as raízes permaneceram crescendo, possivelmente às expensas de substrato mobilizado de outros órgãos.
\end{abstract}

Palavras-chave: Carboidratos, Citrus sinensis, crescimento vegetativo, limoeiro 'Cravo', 'Trifoliata', trocas gasosas.

( $\left.{ }^{1}\right)$ Recebido para publicação em 11 de setembro de 2006 e aceito em 29 de agosto de 2007 .

$\left({ }^{2}\right)$ Curso de Pós-graduação em Agricultura Tropical e Subtropical, Instituto Agronômico de Campinas (IAC). E-mail: zeroagro@yahoo.com.br (Bolsita PIBIC); danifavero@yahoo.com.br (Bolsista FAPESP).

$\left({ }^{3}\right)$ Acadêmico da Universidade Federal de São Carlos (Ufscar), Rua Paul Harris, 500, Araras (SP). E-mail: amaral@cca.ufscar.br

$\left({ }^{4}\right)$ Conplant, Rua Francisco Andreo Aledo, 22 , 13084-200 Campinas (SP) . E-mail: clmedina@conplant.com.br

$\left({ }^{5}\right)$ Centro de Pesquisa e Desenvolvimento em Ecofisiologia e Biofísica, IAC. E-mail: caruso@iac.sp.gov.br ( $\left.{ }^{*}\right)$ Autor correspondente. Bolsita de Produtividade em Pesquisa do CNPq. 


\title{
ABSTRACT \\ WATER DEFICIT, GAS EXCHANGE AND ROOT GROWTH IN `VALENCIA’ ORANGE TREE BUDDED ON TWO ROOTSTOCKS
}

\begin{abstract}
The growth and distribution of the root system affect the response of the plants to water deficit. This work aim at the to evaluation of 'Valencia' orange budded on 'Rangpur' lime and Poncirus trifoliata ('Trifoliata') as to root growth, gas exchange $\left(\mathrm{CO}_{2}\right.$ and $\left.\mathrm{H}_{2} \mathrm{O}\right)$, leaf water potential and distribution of carbohydrates in several organs, in plants submitted to water deficit. Plants were transplanted to 32 rizotrons, which allowed root visualization of the roots. Sixteen plants in each rootstock were submitted to irrigation and the other 16 remained without irrigation. Water deficit was induced withholding the water supply. Stomatal conductance declined after the fourth day without irrigation, causing a reduction of the photosynthesis, the transpiration and the carboxilation efficiency. The total carbohydrate content (sucrose + reducing sugars + starch) in plants without water stress was greater in 'Trifoliata', and among the water deficit treatments it was always less. The dry phytomass of the plants without water deficit was greater in both rootstocks. Among the irrigated and non irrigated treatments, the length of the roots same of rootstocks was similar. However, the root lengths of plants on 'Rangpur' lime were significantly greater than that on 'Trifoliata'. Even under water deficit and great decrease of the photosynthetic production, the roots maintained growth, possibly at the expenses of mobilized substrates of other plant parts.
\end{abstract}

Key words: Carbohydrates, Citrus sinensis, vegetative growth, 'Rangpur' lime, 'Trifoliata', gas exchange.

\section{INTRODUÇÃO}

É comum a ocorrência de deficiência hídrica nas principais regiões citrícolas brasileiras, onde predomina o cultivo sem irrigação (OrTOLANi et al., 1991). A suscetibilidade dos citros à seca se deve ao seu caráter mesofítico, herdado de progenitores provenientes do estrato inferior de florestas úmidas de baixas latitudes. Essas espécies possuem um desenvolvimento foliar abundante. As folhas contêm a maior quantidade de carboidratos da planta e alta densidade de estômatos. $\mathrm{O}$ sistema radicular possui pêlos absorventes atrofiados e baixa condutividade hidráulica, causando um desbalanço entre a absorção de água e a transpiração (KRIEDEMANN e BarRs, 1981; Medina e Machado, 1998a, b; Medina et al., 1999). Sua grande dispersão e a adaptação a regiões sujeitas à deficiência hídrica devem-se ao eficiente controle estomático da planta que limita a transpiração durante as horas com maior demanda hídrica na atmosfera e deficiência hídrica no solo. Entretanto, o fechamento dos estômatos afeta o acesso do carbono atmosférico aos sítios de fixação no mesofilo e a produtividade conseqüente (Kriedemann e Barrs, 1981; Medina et al., 1999).

A adaptação das laranjeiras à deficiência hídrica também é influenciada pelo uso de portaenxertos de diferentes espécies cítricas, gêneros afins e híbridos. Esses porta-enxertos podem modificar o vigor e a produtividade das plantas, a absorção de nutrientes minerais, o balanço hormonal, a qualidade dos frutos, a taxa de assimilação de gás carbônico e a transpiração (CASTLE e KRESDORNM, 1975; WUTSCHER, 1979; Medina e Machado, 1998a,b; Machado e Medina,
1999; Pompeu Junior., 2005). Os porta-enxertos também afetam a tolerância às doenças, à seca, à salinidade e à hipoxia (Lloyd et al., 1987; GuIRADO et al., 1991; POMPEU JUNIOR., 2005).

Apesar da grande variedade de porta-enxertos disponível, a citricultura brasileira está praticamente apoiada no limoeiro 'Cravo' que induz boa produtividade, precocidade de produção, compatibilidade com a maioria das copas comerciais e boa adaptação nas regiões com ocorrência de seca (POMPeU Junior, 2005). No entanto, o predomínio de um porta-enxerto somente é preocupante, à medida que torna o parque citrícola vulnerável a problema semelhante ao que ocorreu na década de 40 , quando o vírus da tristeza dizimou a maioria dos pomares cítricos, enxertados sobre um único porta-enxerto, a laranjeira 'Azeda' (Citrus aurantium L.) (POMPEu JunIOR, 2005). De fato, hoje a citricultura está enfrentando uma séria doença chamada Morte Súbita dos Citros, que afeta principalmente plantas sobre limoeiro 'Cravo'.

A adaptação à seca é função multigênica e depende de várias características fisiológicas e morfológicas (BRAY, 1993). Os motivos pelos quais o limoeiro 'Cravo' se adapta melhor à deficiência hídrica são pouco conhecidos e devem ser analisados para que novos porta-enxertos, com características fenotípicas e fisiológicas semelhantes, possam ser selecionados.

A sobrevivência das plantas terrestres depende da capacidade das raízes em obter água e nutrientes do solo. A tolerância à seca pode ser relacionada com a arquitetura, extensão e com a condutividade 
hidráulica do sistema radicular (Medina et al., 1998; Steudle, 2000; Pinheiro et al., 2005). Essas características são importantes para que a planta extraia mais água do solo, mantendo alto o potencial da água nas folhas, maior turgescência celular e, conseqüentemente, maior eficiência fotossintética (Medina et al., 1999). PinHeIro et al. (2005), observaram que a tolerância à seca em cafeeiros está relacionada à profundidade das raízes e ao controle estomático.

A arquitetura radicular e sua capacidade de exploração das camadas mais profundas e úmidas do solo, juntamente com maior razão entre a raiz e parte aérea, são características importantes de escape aos déficits hídricos. Dependendo do porta-enxerto, as raízes podem crescer até $5 \mathrm{~m}$ de profundidade, embora a maior quantidade se encontre próxima à superfície do solo (SPIEgel-Roy e GoldschimidT, 1996). A maior tolerância à seca de plantas cítricas enxertadas sobre limoeiro 'Rugoso' (Citrus jambhiri Lush.) foi associada à maior profundidade de suas raízes (SPIEgel-Roy e GoldsCHIMIDT, 1996).

A continuidade do crescimento radicular, sob condições de menor disponibilidade hídrica, depende da manutenção de uma pressão de turgor mínima nas células, que seja suficiente para permitir o alongamento da parede celulósica e o crescimento celular (Hsiao e $X_{U}, 2000$ ). Quando o potencial da água é reduzido nas raízes, verifica-se em várias espécies um rápido ajuste osmótico, auxiliando o restabelecimento da pressão de turgor e permitindo a manutenção do alongamento celular. Em contraste, o ajuste osmótico nas folhas ocorre mais lentamente, levando à diminuição ou à parada da extensão das paredes celulares e ao menor crescimento da parte aérea (Hsiao e Xu, 2000).

Neste trabalho, o objetivo foi medir comparativamente em laranjeira 'Valência' sobre dois tipos de porta-enxerto, limoeiro 'Cravo' e sobre 'Trifoliata', submetida à deficiência hídrica as seguintes variáveis: a) crescimento de raízes; b) acúmulo de massa seca, c) trocas gasosas e relações hídricas e d) distribuição de carboidratos.

\section{MATERIAL E MÉTODOS}

A pesquisa foi desenvolvida em casa de vegetação localizada no Centro Avançado de Pesquisa Tecnológica dos Agronegócios de Citros 'Sylvio Moreira' (IAC) em Cordeirópolis (SP). Utilizaram-se laranjeira 'Valência', de aproximadamente um ano, sobre dois tipos de porta-enxertos: limoreiro 'Cravo' (Citrus limonia L.) ['Cravo'] e Poncirus trifoliata (clone Rubidoux) ['Trifoliata']. As laranjeiras foram transplantadas para 32 rizotrons, sendo 16 para cada tipo de porta-enxerto, onde permaneceram por todo o período experimental. O delineamento experimental foi em blocos ao acaso com oito repetições. Os tratamentos foram dois tipos de porta-enxerto com e sem estresse hídrico, com oito repetições por tratamento. Cada parcela foi representada por uma planta no rizotron.

Os rizotrons possuem um plano de visão transparente para o monitoramento e a quantificação do sistema radicular das plantas possuindo $1 \mathrm{~m}$ de altura e diâmetro com $0,25 \mathrm{~m}$, em formato de semicírculo, contendo uma parede dupla na face reta. A parede interna é de vidro transparente com $4 \mathrm{~mm}$ de espessura para permitir a visualização do sistema radicular e a externa é de madeira que impede a passagem de luz. Essas paredes são facilmente removidas, pois podem correr em canaletas fixas à parede do tubo semicircular. Os rizotrons foram posicionados com 85 graus de inclinação em relação ao piso, possibilitando o crescimento das raízes junto da face transparente e facilitando a visualização das raízes e a obtenção das medidas. Os rizotrons foram preenchidos com terra corrigida para um $\mathrm{pH}$ próximo a 6,0 com calcário, permitindo bom fornecimento de cálcio e ausência de alumínio tóxico solúvel. As plantas foram fertilizadas semanalmente com nitrogênio e cálcio, utilizando-se duas aplicações de 1 litro de solução de nitrato de cálcio na dose de $5 \mathrm{~g}$ do fertilizante por litro de água, o que forneceu às plantas $1,55 \mathrm{~g}$ de nitrogênio e 1,9 g de cálcio.

Vinte dias após o transplante, realizado em 12/1/2006, interrompeu-se a irrigação em 16 rizotrons, oito para cada tipo de porta-enxerto. A partir da suspensão da irrigação mediu-se, às $9 \mathrm{~h}$, a assimilação de $\mathrm{CO}_{2}$ e a taxa de transpiração e a condutância estomática, com um analisador portátil de fotossíntese (Li-6400, Licor Ltda., Lincoln-NE) na densidade de fluxo de fótons fotossintéticos igual a $1500 \mu \mathrm{mol} \cdot \mathrm{m}^{-2} \cdot \mathrm{s}^{-1}$. Também mediu-se o potencial de água nas folhas $\left(\Psi_{1}\right)$, com câmara de pressão, às $6 \mathrm{e}$ às 14 horas, a cada três dias, pelo método de KaUfmanN (1968). Utilizou-se nestas medidas uma folha totalmente desenvolvida, com idade entre quatro e seis meses.

Em cada rizotron, através da parede de vidro, selecionaram-se 10 raízes e em intervalos de três dias mediu-se o comprimento pelo plano de visão, com uma régua. As medidas foram coletadas entre $12 / 1$ e 10/ $3 / 2006$. No término do experimento, as plantas foram retiradas dos rizotrons, lavadas e separadas a raiz da parte aérea para obtenção da sua massa seca, após secagem em estufa por 7 dias a $60^{\circ} \mathrm{C}$. 
Para a análise de açúcares, foram coletadas folhas, caule e raízes no desmonte dos rizotrons $(10 / 3 / 2006)$. Folhas, pedaços de caule relativos à da parte inferior, mediana e apical e porções de raízes foram coletadas para análise de carboidratos. Imediatamente após a coleta, as amostras de folhas e caules foram imersas em gelo seco. As amostras de raízes foram lavadas e em seguida também imersas em gelo seco. As amostras foram conservadas a $-20{ }^{\circ} \mathrm{C}$ até o momento das análises. Antes da elaboração do extrato para análise, as folhas, caules e raízes foram submetidos à secagem em estufa com circulação forçada de ar à temperatura de $60{ }^{\circ} \mathrm{C}$ por 4 dias, até massa constante. $\mathrm{O}$ extrato para análise de açúcares redutores, sacarose e açúcares solúveis totais foi obtido a partir da extração alcoólica $(100 \mathrm{mg}$ de amostra seca moída com $5 \mathrm{~mL}$ de etanol $80 \%$ ) durante 4 horas em banho-maria a $50{ }^{\circ} \mathrm{C}$. A determinação do teor de açúcares foi feito por HPLC, em coluna Dionex P1, tendo como solvente $\mathrm{NaOH}$ $40 \mathrm{mM}$ com fluxo de $0,8 \mathrm{~mL} / \mathrm{min}$, e detecção em detector de pulso amperométrico. A análise de amido foi feita no resíduo do precipitado após banho-maria a $50{ }^{\circ} \mathrm{C}$. A extração do amido no resíduo precipitado foi feita com $5 \mathrm{~mL}$ de ácido perclórico a $30 \%$ por três vezes consecutivas, a 50 ${ }^{\circ} \mathrm{C}$ por 20 minutos cada uma. O amido foi determinado com uso de regente de antrona 0,1\% em ácido sulfúrico 95\% (Yemm e Willis, 1954).

A quantificação da necessidade de água a ser aplicada no tratamento irrigado foi feita a cada dois dias por meio de pesagens. A diferença das massas entre os dois dias foi considerada como a quantidade de água evapotranspirada e a ser reposta.

O delineamento experimental foi em blocos ao acaso com oito repetições e efetuou-se a análise de variância utilizando-se o programa Origin 7.5 e as médias foram comparadas pelo teste de Tukey a $5 \%$.

\section{RESULTADOS E DISCUSSÃO}

A assimilação máxima de $\mathrm{CO}_{2}(\mathbf{A})$ foi de 12,5 e $11,8 \mu \mathrm{mol} \mathrm{m}^{-2} \mathrm{~s}^{-1}(\mathrm{p}<0,05)$ em laranjeiras 'Valência' sobre 'Cravo' e laranjeira 'Valência' sobre 'Trifoliata' respectivamente, no tratamento sem deficiência hídrica. A transpiração (E) foi 4,1 e $3,8 \mathrm{mmol} \mathrm{m}^{-2} \mathrm{~s}^{-1}$, respectivamente, para 'Cravo' e 'Trifoliata'. Os maiores valores de trocas gasosas foram relacionados ao maior valor da condutância estomática $(g s, p<0,05)$ nas plantas sobre 'Cravo' $\left(0,21 \mathrm{~mol} \mathrm{~m}^{-2} \mathrm{~s}^{-1}\right)$ em relação à 'Trifoliata' $\left(0,17 \mathrm{~mol} \mathrm{~m}^{-2} \mathrm{~s}^{-1}\right)$, visto que as eficiências de carboxilação foram semelhantes para ambos os porta-enxertos (Figura 1). Antes da interrupção da irrigação observaram-se que os valores máximos do potencial da água na folha foram ao redor de - $0,2 \mathrm{MPa}$ na medida da pré-manhã e ao redor de - $0,7 \mathrm{MPa}$ à tarde, em ambos os tipos de porta-enxertos.
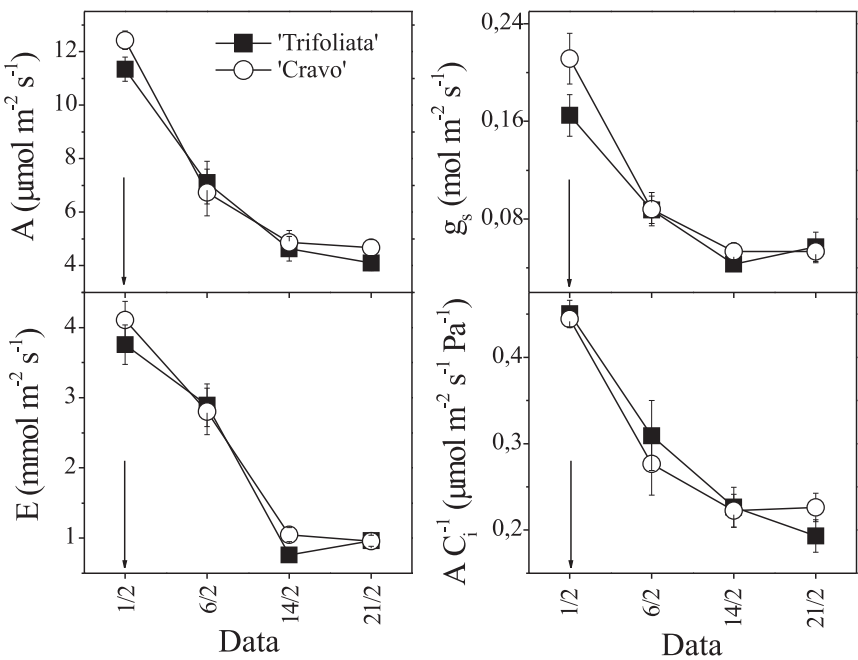

Figura 1. Resposta da assimilação de $\mathrm{CO}_{2}(\mathbf{A})$, transpiração (E), condutância estomática $\left(\mathrm{g}_{\mathrm{s}}\right)$ e eficiência instantânea de carboxilação $\left(\mathbf{A} \mathbf{C i}^{-1}\right)$ em laranjeira 'Valência' sobre limoeiro 'Cravo' ou 'Trifoliata' em função da interrupção da irrigação. Seta indica dia da interrupção da irrigação e barras o desvio-padrão.

Após o início da interrupção da irrigação o padrão de resposta das trocas gasosas e de gs, em relação ao número de dias sem irrigação, nos dois porta-enxertos foi semelhante, ou seja os valores de A, de $\mathbf{E}$ e de gs diminuíram em função do número de dias sem irrigação. O mesmo ocorreu com a eficiência instantânea de carboxilação, cujos valores máximos, em ambos os porta-enxertos ocorreram antes do início da suspensão da irrigação e diminuíram progressivamente em função da deficiência hídrica crescente (Figura 1). MEdina e MACHADO (1998) também observaram queda na atividade metabólica da fotossíntese em laranjeira sob estresse hídrico. Sob deficiência hídrica as variáveis relacionadas com as trocas gasosas não diferiram entre tipos de portaenxertos (Figura 1).

Após a interrupção da irrigação ocorreu queda no conteúdo de água na terra do rizotron em função da evapotranspiração, evidenciado pela perda de massa no rizotron entre as pesagens (resultado não apresentado). A queda progressiva da disponibilidade de água na terra causou queda no potencial da água na folha (Figura 2) devido a um desbalanço entre a água absorvida pelo sistema radicular e a transpirada pelas folhas, causando queda no conteúdo relativo de água na folha. Esta situação também acarretou em fechamento parcial dos estômatos, indicado pela 
redução da condutância estomática (Figura 1) que implica, por sua vez, em queda da transpiração e da assimilação de $\mathrm{CO}_{2}$, visto que ambos são processos difusivos (Figura 1).
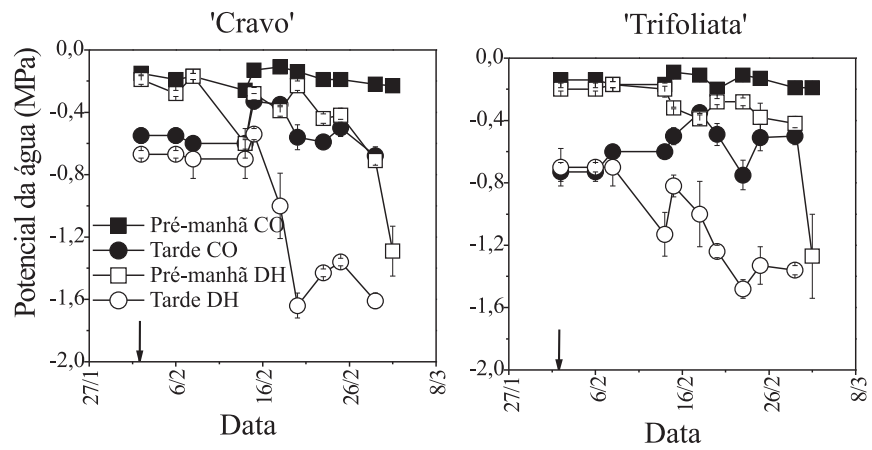

Figura 2. Potencial da água na folha em laranjeira 'Valência' sobre limoeiro 'Cravo' ou 'Trifoliata' em função da interrupção da irrigação. Siglas $\mathrm{CO}$ e $\mathrm{DH}$ indicam, respectivamente, controle e deficiência hídrica. Seta indica dia da interrupção da irrigação e barras o desvio- padrão.

Até o quarto dia após a interrupção da irrigação a queda em gs foi alta, porém a queda em $\Psi_{1}$ ocorreu somente a partir $12 .^{\circ}$ dia, ou seja, a condutância estomática foi mais responsiva à queda da umidade do solo do que $\Psi_{1}$. Esse processo também foi evidenciado em laranjeira (MACHADO E MEdina, 1999; Gomes ET AL., 2003) e em outras espécies (TARDIEU et al., 1992, DAviEs et al., 1994). Esse fato está coerente com a hipótese de que há uma comunicação química entre a raiz e a parte aérea, provocando o movimento estomático, conforme sugerem vários autores. Sugerese que esse sinal seja intermediado por substâncias de crescimento, possivelmente o ácido abscísico, produzido nas raízes (TARDIEU et al., 1992; DAVIES et al., 1994; Gomes et al., 2003). Esse tipo de resposta permite a manutenção de água na folha por um período maior, quando o solo esta em processo de secamento progressivo.

A queda dos processos de trocas gasosas foi progressiva no sentido de aproximar-se de zero. A assimilação de $\mathrm{CO}_{2}$ decaiu tanto em função do fechamento parcial dos estômatos como devido à queda da eficiência instantânea de carboxilação (Figura 1). Após o $12{ }^{\circ}$ dia da suspensão da irrigação o $\Psi_{1}$ diminuiu nas folhas das copas sobre os dois tipos de porta-enxertos, atingindo seu menor valor em 20/ 2 , sobre o limoeiro 'Cravo' e em 26/2 sobre 'Trifoliata' (Figura 2). Conforme já observado por Medina e Machado (1998), o potencial da água na folha da planta sobre 'Cravo' decresceu mais rápida e intensamente do que sobre 'Trifoliata'. Possivelmente a queda mais rápida em 'Cravo' esteja relacionada com seu desenvolvimento mais rápido e maior quantidade de folhas (Figura 3). A manutenção de baixos potenciais de água na planta (Figura 2) contribuiu para a baixa taxa de assimilação de $\mathrm{CO}_{2}$ em função do fechamento parcial dos estômatos e da queda na eficiência de carboxilação (Figura 1).

O fechamento dos estômatos é a primeira linha de defesa da planta para enfrentar a deficiência hídrica do solo, pois este mecanismo restringe a perda de água por meio da transpiração, mas ao mesmo tempo em que esse processo ocorre também há queda na assimilação de $\mathrm{CO}_{2}$, por meio do processo fotossintético. O fechamento dos estômatos ocorre devido à desidratação das células-guarda, ou por resposta hormonal. Para ambos os tipos de portaenxertos o padrão de resposta foi semelhante.

O substrato orgânico utilizado para o crescimento das plantas é proveniente do processo fotossintético. Assim, as laranjeiras sob estresse progressivo praticamente ficaram sem produção de substrato para o crescimento. Outras linhas de defesas frente à ocorrência de estresse hídrico, como crescimento de raízes, devem ocorrer às expensas de reservas na planta.

A queda da assimilação de $\mathrm{CO}_{2}$ refletiu-se no acúmulo de fitomassa nas plantas (Figura 3). $\mathrm{Na}$ figura 3, observa-se que a laranjeira 'Valência' sobre 'Cravo' sem estresse acumulou uma maior quantidade de fitomassa total e nos seus diversos órgãos do que sobre em 'Trifoliata' $(p<0,05)$. Em ambos os tipos de porta-enxertos sob deficiência hídrica, as plantas acumularam menor quantidade de fitomassa. É importante observar que as massas das raízes foram semelhantes entre o limoeiro 'Cravo' com e sem deficiência hídrica, enquanto em 'Trifoliata' com deficiência hídrica, ocorreu massa de raízes menor (Figura 3). Excetuando as raízes de 'Cravo', em todos outros órgãos no tratamento sob deficiência hídrica houve menor acúmulo de fitomassa (Figura 3), confirmando o efeito da queda da fotossíntese sobre o crescimento.

Na figura 4 , observa-se a dinâmica do crescimento das raízes nas duas espécies de portaenxerto com e sem deficiência hídrica. Apesar da queda de fotossíntese, em ambos os tipos de portaenxertos as raízes das plantas sob estresse cresceram em extensão tanto quanto as das plantas sem deficiência hídrica. Quando há queda do conteúdo de água no substrato de crescimento pode ocorrer ajuste osmótico das raízes ocorrendo recuperação da turgescência das raízes e restabelecendo o gradiente de potencial para absorção de água e crescimento das raízes (Hsiao e Xu, 2000). 


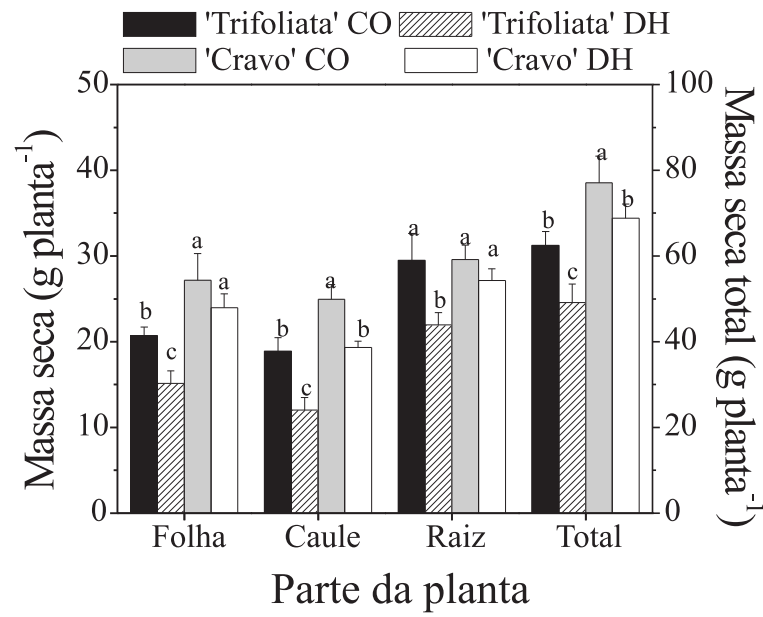

Figura 3. Massa seca final das folhas, caules, raízes e total em laranjeira 'Valência' sobre limoeiro 'Cravo' ou 'Trifoliata' em função da interrupção da irrigação. Siglas CO e DH indicam, respectivamente, controle e deficiência hídrica. Letras iguais indicam igualdade estatística ao nível de 5\% pelo teste Tukey.

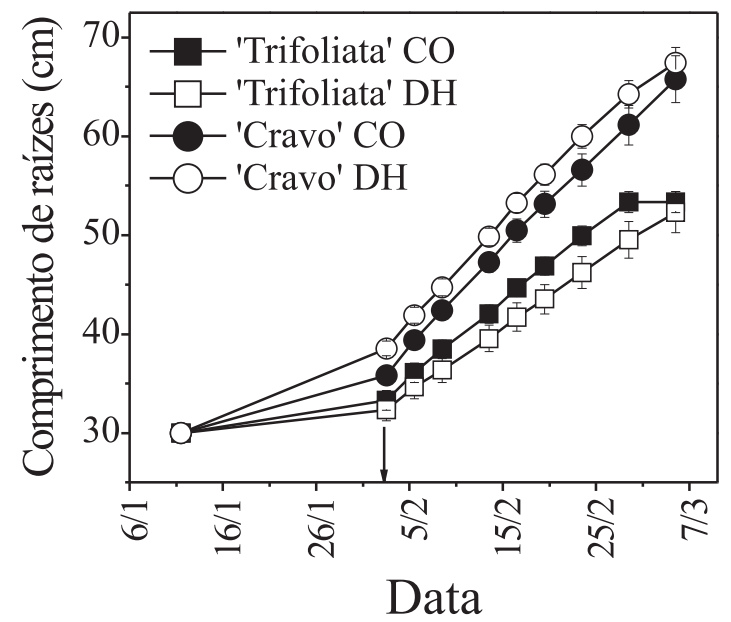

Figura 4. Crescimento de raízes em laranjeira 'Valência' sobre limoeiro 'Cravo' ou 'Trifoliata' em função da interrupção da irrigação. Siglas CO e DH significam, respectivamente, controle e deficiência hídrica. Seta indica dia da interrupção da irrigação e barras o desvio-padrão.

Em ambos os tipos de porta-enxertos, quando as plantas foram transplantadas para o rizotron, o comprimento das raízes era $30 \mathrm{~cm}$, limitado pelo tamanho do vaso de formação de mudas. No fim do experimento, desenvolveu-se em 'Cravo' raízes $1,3 \mathrm{vez}$ $(p<0,05)$ mais compridas que em 'Trifoliata' no tratamento com e no sem deficiência hídrica. Como a massa seca das raízes de 'Trifoliata' submetida à deficiência hídrica foi menor, as raízes sob estresse devem ser mais finas. Hsiao e $\mathrm{Xu}_{\mathrm{U}}$ (2000), também observaram raízes mais finas sob estresse hídrico. Já em 'Cravo', pelo menos neste período de experimentação, tanto a massa das raízes como o comprimento final foram semelhantes às plantas não estressadas. Esse tipo de resposta do 'Cravo' e do 'Trifoliata' indica a existência de um mecanismo de adaptação à seca, priorizando o crescimento das raízes sob estresse hídrico. Esse mecanismo adaptativo foi mais eficiente em 'Cravo', visto que seu crescimento foi mais intenso.

O teor de carboidratos totais (sacarose + açúcares redutores + amido) foi maior nas folhas. Nas raízes e nos colmos, observaram teores semelhantes (Figura 5). Em relação ao amido, que é o principal carboidrato de reservas, os maiores teores foram observados nas folhas e nas raízes. Sacarose, a principal forma de transporte de carboidratos, é bem maior nas folhas que nas raízes e caules.

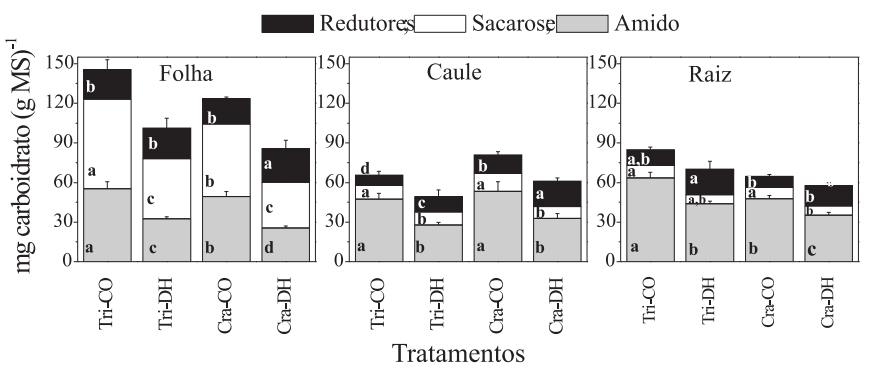

Figura 5. Teor de amido, açúcares redutores e sacarose na fitomassa seca de folhas, caules, raízes e total em laranjeira 'Valência' sobre limoeiro 'Cravo' (Cra) ou 'Trifoliata' (Tri) submetida (DH) ou não (CO) à deficiência hídrica. Letras diferentes dentro da mesma coluna significam diferença estatística ao nível de 5\% pelo teste Tukey.

Em todos os órgãos, o teor total de carboidrato foi menor nas plantas sob deficiência hídrica (Figura 5). Os menores teores de carboidratos nas plantas sob estresse está relacionado à menor assimilação de $\mathrm{CO}_{2}$ e à mobilização de reservas para o crescimento e à manutenção das plantas sob estresse. De fato, a massa seca total e dos órgãos individualmente foram menores nas plantas sob estresse, no entanto, as raízes cresceram em comprimento e relativamente mais em massa do que na parte aérea. As relações parte aérea/raízes foram de 0,64 e 0,81 para o 'Cravo' e de 0,59 e 0,63 para o 'Trifoliata', respectivamente, sem e com deficiência hídrica. 
Assim, o crescimento das raízes em plantas sob estresse com pequena produção fotossintética deve ter ocorrido devido a dois fatos principais: $10^{\circ}$ ) direcionamento preferencial dos fotoassimilados recém-produzidos para as raízes e b) mobilização de reservas de outros órgãos para as raízes. Tanto em 'Cravo' como em 'Trifoliata' a diferença entre o amido acumulado nas plantas-controle em relação àquelas com deficiência foi ao redor de $60 \mathrm{mg}$ de amido por $\mathrm{g}$ de fitomassa seca. Essa diferença na quantidade de amido é significativa e possivelmente manteve o crescimento das raízes. É importante destacar que a massa de raízes e o comprimento de raízes em 'Cravo' foram semelhantes entre plantascontrole e sob estresse. Também em 'Cravo' houve maior capacidade de crescimento das raízes em relação ao 'Trifoliata'. Esses resultados indicam que pelo menos em parte a maior tolerância do 'Cravo' pode estar relacionada à sua capacidade de crescimento de raízes.

\section{CONCLUSÕES}

1. A deficiência hídrica diminui a capacidade fotossintética das plantas devido à queda na condutância estomática e à eficiência instantânea de carboxilação. A redução do potencial da água nas plantas sob estresse hídrico contribuiu para o abaixamento da fotossíntese, condutância estomática, transpiração e eficiência de carboxilação.

2. A queda na assimilação de $\mathrm{CO}_{2}$ causou redução na fitomassa e teores de carboidratos acumulados.

3. Mesmo com deficiência hídrica, o comprimento das raízes analisadas foi semelhante às do tratamento controle, em ambos os portaenxertos.

4. A massa seca nos tratamentos-controle foi sempre maior em relação aos tratamentos com déficit hídrico.

5. A laranjeira 'Valência' sobre limoeiro 'Cravo' teve o sistema radicular mais desenvolvido em relação ao 'Trifoliata', tanto no controle como na deficiência hídrica. É possível, portanto, que a maior tolerância à seca conferida às laranjeiras sobre 'Cravo' esteja relacionado a este fator.

\section{AGRADECIMENTOS}

Ao CNPq pela concessão de bolsas PIBIC e de Produtividade Científica; à FAPESP pela concessão de bolsa de mestrado e pelo financiamento do projeto.

\section{REFERÊNCIAS}

BRAY, E.A. Update on water deficit. Molecular responses to water deficit. Plant Physiology, Rockville, v. 103, p.1035-1040, 1993.

CASTLE, W.S. e KRESDORNM, A. H. Effects of citrus rootstock on root distribution and leaf mineral content of Orlando tangelo trees. Journal of American Society for Horticultural Science, Alexandria, v. 100, p.1-4, 1975.

DAVIES, W.J.; TARDIEU, F. e TREJO, C.L. How do chemical signal work in plants that grow in drying soil? Plant Physiology, Rockville, v. 104, p.309-314, 1994.

GOMES, M.M.A.; LAGOA, A.M.M.A., MACHADO, E.C.; MEDINA, C.L. Abscisic acid and indole-3-acetic acid contents in orange trees infected by Xylella fastidiosa and submitted to cycles of water stress. Plant Growth Regulation, Dordretch, v. 39, p. 263-270, 2003.

GUIRADO, N., MULLER, G.W.; PRATES, H. S. Declínio dos citros. In: RODRIGUES, O., VIÉGAS, F., POMPEU JÚNIOR; AMARO, A.A. (Ed.). Citricultura brasileira. 2. ed. Campinas: Fundação Cargill, 1991. p. 722-734.

HSIAO, T.C.; XU, L.K. Sensitivity of growth of roots versus leaves to water stress: biophysical analysis and relation to water transport. Journal of Experimental Botany, Oxford, v. 51, p.1595-1616, 2000.

KIEDEMANN, P.E.; BARRS, H.D. Citrus orchads. In: KOZLOWSKI, T.T. (Ed.). Water deficits and plant growth. VI. Woody plant communities, 1981. p. 325-418,

LLOYD, J. KRIEDEMANN, P.E.; SYVERTSEN, J.P. Gas exchange, water relations and ion concentration of leaves on salt stressed 'Valencia' orange, Citrus sinensis (L.) Osbeck. Australian Journal of Plant Physiology, Victoria, v.14, p. 387396, 1987.

MACHADO, E.C.; MEDINA, C.L. Teor de água no substrato de crescimento e fotossíntese em laranjeira 'Valência' . Bragantia, Campinas, v. 58, p. 217-226, 1999.

MEDINA, C. L.; MACHADO, E. C. Trocas gasosas e relações hídricas de laranjeira 'Valência', enxertada sobre limoeiro "Cravo" e Poncirus "Trifoliata", submetida a deficiência hídrica. Bragantia, Campinas, v.57, p. 1-14, 1998a.

MEDINA, C. L.; MACHADO, E. C. Fotossíntese de laranjeira 'Valência' enxertada sobre quatro porta-enxertos e submetida a deficiência hídrica. Bragantia, Campinas, v. 57, p. 15-22, 1998 b.

MEDINA, C. L.; MACHADO, E. C.; GOMES, M.M.A. Condutância estomática, transpiração e fotossíntese em laranjeira 'Valência' sob deficiencia hídrica. Revista Brasileira de Fisiologia Vegetal, Londrina, v. 11, p. 29-34, 1999.

ORTOLANI, A.A., PEDRO JUNIOR, M.J.; ALFONSI, R.R.. Agroclimatologia e o cultivo de citros. In: RODRIGUES, O., VIÉGAS, F., POMPEU JUNIOR; AMARO, A.A. (Eds.). Citricultura brasileira. 2. ed. Campinas: Fundação Cargill, 1991. p. 153-195. 
POMPEU Jr., J. Porta-enxertos. In: MATTOS JUNIOR, D.; DENIGRI, J.D. PIO, R.M.; POMPEU JR, J. (Eds). Citros. Campinas, 2005. p. 61-104.

SPIEGEL-ROY, P.; GOLDSCHMIDT, E.E. Biology of citrus. First edition. Cambridge: University Press, 1996. 230 p.

STEUDLE, E. Water uptake by roots: effects or water deficit. Journal of Experimental Botany, Oxford, v. 51, p. 1531$1542,2000$.

TARDIEU, F.; ZHANG, J.; KATERJI, N.; BETHENOD, O., PALMER, S.; DAVIES, W.J. Xylem ABA controls the stomatal conductance of field-grow maize as a function of the predraw leaf water potential. Plant Cell and Environment, Oxford, v, 15, p. 193-197, 1992.
WUTSCHER, H.K. Citrus rootstocks. Horticultural Review, Hoboken, v. 1, p. 237-269, 1979.

YEMM, E.W.; WILLIS, A.J. The estimation of carbohydrates in plant extracts by anthrone. Journal of Experimental Botany, Oxford, v. 44, p. 508-514, 1954. 